\title{
Clustering phenomena in low-pressure reactive plasmas. Basis and applications*
}

\author{
Y. Watanabe ${ }^{\ddagger}$, M. Shiratani, and K. Koga \\ Faculty of Information Science and Electrical Engineering, Kyushu University, \\ Fukuoka 812-8581, Japan
}

Abstract: Clustering phenomena of particles below a few $\mathrm{nm}$ in size in low-pressure reactive plasmas have been studied in capacitively coupled high-frequency $\mathrm{SiH}_{4}$ discharges. Clusters nucleate around a size of $0.5 \mathrm{~nm}, \mathrm{Si}_{4} \mathrm{H}_{x}$ and subsequently grow due to influxes of $\mathrm{Si}_{n} \mathrm{H}_{x}(1<n<4)$ and other molecular species. Because of long gas-residence time and small surface loss-probability of clusters, even neutral ones accumulate to nucleate in the reactor. Appearance of negatively charged clusters is considered to become noticeable at around $\mathrm{Si}_{4} \mathrm{H}_{x}$. The growth of clusters is suppressed by using thermophoretic force, gas flow, periodical discharge modulation, and hydrogen dilution. The reactor has been newly developed to suppress the growth of clusters both by thermophoretic force and by gas flow and evacuation without stagnation. Using the reactor, a-Si:H films of extremely high quality have been successfully deposited.

\section{INTRODUCTION}

Formation kinetics of particles in reactive plasmas has been extensively studied using capacitively coupled high-frequency (CCHF) $\mathrm{SiH}_{4}$ discharges during the last decade. At present, the kinetics has been fairly well understood for particles above a few $\mathrm{nm}$ in size [1], and some techniques utilizing it have been proposed to prepare functional powder-materials or films, as represented by a high-quality solar cell utilizing $\mathrm{nm}$-size crystallized particles in argon-diluted $\mathrm{CCHF} \mathrm{SiH}_{4}$ discharges [2]. However, many issues have been left concerning the growth kinetics of clusters, particles below a few $\mathrm{nm}$ in size, because there is no method to observe their growth. Understanding of such kinetics is important from viewpoints of their growth suppression and utilization. To study such issues, we have developed two methods for observing in situ time-evolution of size and density of clusters: photon-counting laser-lightscattering method applicable in a nm-size range and double-pulse-discharge method applicable in a sub$\mathrm{nm}$-size range [3,4]. Using the methods, we have succeeded in observing a critical size at which clusters nucleate, and revealed the reasons why the discharge modulation, substrate heating, gas flow, and hydrogen dilution are effective in suppressing the cluster growth.

Recently, we also have developed a reactor which can suppress effectively growth of clusters both using thermophoretic force and realizing gas flow and evacuation without stagnation. The qualities of a-Si:H films deposited with this reactor are much improved as compared to that prepared under the conventional so-called "device-quality" conditions. In this paper, we discuss the growth kinetics and suppression of clusters based on the experimental results obtained using the newly developed observation methods, and show that extremely high-quality a-Si:H films can be prepared by suppressing the cluster growth.

\footnotetext{
*Lecture presented at the $15^{\text {th }}$ International Symposium on Plasma Chemistry, Orléans, France, 9-13 July 2001. Other presentations are presented in this issue, pp. 317-492.

¥Corresponding author: E-mail: watanabe@ed.kyushu-u.ac.jp
} 


\section{CLUSTERING PHENOMENA IN CCHF $\mathrm{SiH}_{4}$ DISCHARGES}

Figure 1 shows size, density, and volume fraction of clusters in a $\mathrm{CCHF} \mathrm{SiH}_{4}$ discharge [4]. There exist two size-groups of clusters: a small size-group which has a constant average size of about $0.5 \mathrm{~nm}$ and a density of $10^{10}-10^{11} \mathrm{~cm}^{-3}$ during the discharge duration; a large size-group which appears at a time $t \sim 10 \mathrm{~ms}$ after the discharge initiation and grows up to a few $\mathrm{nm}$ at $t=0.5 \mathrm{~s}$, and has a tendency that its density decreases from about $10^{10} \mathrm{~cm}^{-3}$ to about $10^{9} \mathrm{~cm}^{-3}$ due to coagulation. The volume fraction increases monotonously even when coagulations between clusters in large sizegroup exist. Since clusters of $0.5 \mathrm{~nm}$ in size almost correspond to $\mathrm{Si}_{n} \mathrm{H}_{x}(n=4)$, the result indicates that the clusters in small size-group nucleate around $\mathrm{Si}_{4} \mathrm{H}_{x}$ 's. The large clusters $\mathrm{Si}_{n} \mathrm{H}_{x}$ 's $(n>4)$ grow by influxes of $\mathrm{Si}_{n} \mathrm{H}_{x}$ 's $(n<4)$ and other molecular species and/or by coagulation between themselves. The density of clusters observed is quite high compared to that of positive ions, about $10^{9} \mathrm{~cm}^{-3}$, in the plasma, and further the density of electrons measured using a microwave interferometer is about $80 \%$ of positive ions, measured carefully with an rf-compensated Langmuir probe, during the discharge. According to ref. [5], the effective attachment rate to clusters tends to increase drastically around a size of $\mathrm{Si}_{4} \mathrm{H}_{x}$. This suggests that almost all of $\mathrm{Si}_{n} \mathrm{H}_{x}$ 's $(n<4)$ are neutral, and some fraction of $\mathrm{Si}_{n} \mathrm{H}_{x}$ 's $(n<4)$ are charged negatively. In these experiments, the following conditions are satisfied: a cluster growth time is much shorter than a gas residence time $T_{\text {res; }}$; a cluster diffusion time to the reactor wall is also much shorter than $T_{\text {res }}$; a surface loss-probability of clusters to the wall, which is deduced from their loss rate after turning off the discharge, is much smaller than unity. Thus, even $\mathrm{Si}_{n} \mathrm{H}_{x}$ 's $(n<4)$ being almost neutral can stay in the reactor during a period long enough for them to nucleate. The growth up to $\mathrm{Si}_{4} \mathrm{H}_{x}$ is considered to be due to the $\mathrm{SiH}_{2}$ insertion reactions.

A series of such results can be reasonably explained by the following growth model: (1) the short lifetime radicals, especially $\mathrm{SiH}_{2}$ 's, generated mainly around the plasma/sheath $(\mathrm{P} / \mathrm{S})$ boundary near the powered electrode react rapidly with $\mathrm{SiH}_{4}$ 's to produce $\mathrm{Si}_{n} \mathrm{H}_{x}$ 's $(1<n<4)$; (2) the $\mathrm{Si}_{n} \mathrm{H}_{x}$ 's $(1<n<4)$ accumulate to nucleate in the reactor because of small surface loss-probability to the reactor wall and long gas-residence time; and (3) the nucleated $\mathrm{Si}_{n} \mathrm{H}_{\mathrm{x}}$ 's $(n<4)$, some fraction of which are charged negatively, grow by influxes of $\mathrm{Si}_{n} \mathrm{H}_{x}$ 's $(1<n<4)$ and other molecular species.

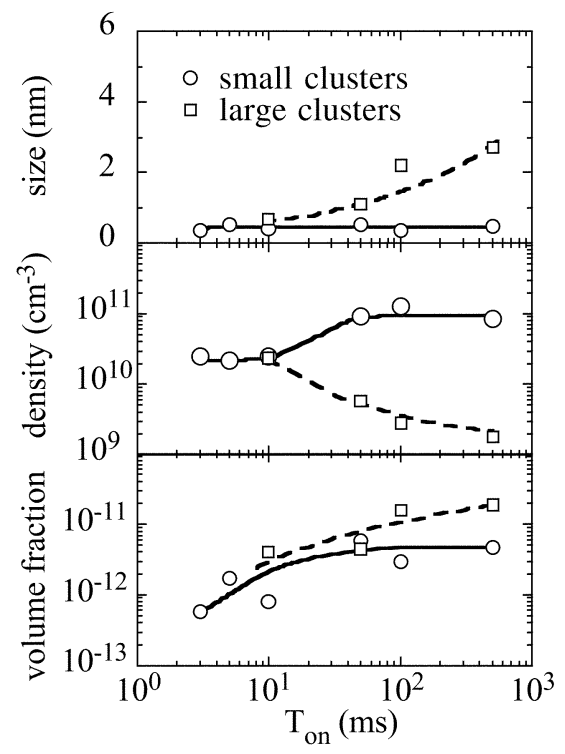

Fig. 1 Time evolution of size, density, and volume fraction of clusters after discharge initiation. Experimental conditions: $100 \% \mathrm{SiH}_{4}, 13.3 \mathrm{~Pa}, 5 \mathrm{sccm}(17 \mathrm{~cm} / \mathrm{s}), 10 \mathrm{~W}\left(0.18 \mathrm{~W} / \mathrm{cm}^{2}\right), 13.56 \mathrm{MHz}$. 
Our experiments have shown a lot of clusters exist even under the conventional device-quality conditions. This implies that some fraction of them are incorporated into depositing films, resulting in their quality deterioration. To suppress deposition of such clusters into films, we have experimentally studied effects of substrate heating, gas flow, discharge modulation, and hydrogen dilution on cluster growth. From these studies, we have obtained the following results: (1) the gas temperature gradient due to heating the grounded electrode is effective in driving clusters above a few $\mathrm{nm}$ in size toward the powered electrode of room temperature as shown in Fig. 2 [6]; (2) the gas flow across the radical generation-region around the P/S boundary, is effective in suppressing the cluster growth [7]; (3) the periodical discharge modulation is effective in suppressing the density of clusters when a discharge-off time in one discharge period is long enough compared to a diffusion time of clusters through the radical generation-region [6]; and (4) the hydrogen dilution is effective in suppressing coagulation between clusters in the large size-group [6].

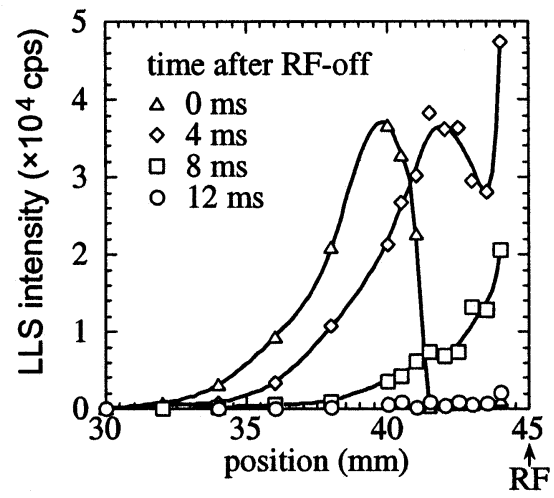

Fig. 2 Transport of clusters toward powered electrode by grounded electrode heating. Experimental conditions: $100 \% \mathrm{SiH}_{4}, 13.3 \mathrm{~Pa}, 5 \mathrm{sccm}, 8 \mathrm{~W}\left(0.1 \mathrm{~W} / \mathrm{cm}^{2}\right)$, grounded electrode $300{ }^{\circ} \mathrm{C}$.

\section{QUALITY IMPROVEMENT OF a-SI:H FILMS BY SUPPRESSING CLUSTER GROWTH}

Clustering phenomena in reactive plasmas are important from two aspects: utilization of them for preparing powder materials of novel or tailored functions and/or high-quality films [2]; production of high-quality films by suppressing cluster growth. Recently, from the latter aspect, we have made a reactor for a-Si:H film deposition, as shown in Fig. 3, in which growth of clusters is suppressed due to gas temperature gradient, gas flow across the radical generation region, and evacuation through both the powered electrode with many holes and four viewing ports on the reactor wall [8]. Figure 4 shows gas-flow-rate dependences of both the ratio $R_{\alpha}$ of absorption intensity of $\mathrm{Si}-\mathrm{H}_{2}$ stretching mode $\left(2100^{-1} \mathrm{~cm}\right)$ to that of $\mathrm{Si}-\mathrm{H}$ one $\left(2000^{-1} \mathrm{~cm}\right)$, and the $\mathrm{Si}-\mathrm{H}_{2}$ hydrogen content $\mathrm{C}_{\mathrm{H}}\left(\mathrm{Si}-\mathrm{H}_{2}\right)$ and total hydrogen content $\mathrm{C}_{\mathrm{H}}\left(\mathrm{Si}-\mathrm{H}_{2}+\mathrm{Si}-\mathrm{H}\right)$, respectively. While the ratio $R_{\alpha}$ for a-Si:H films under the conventional device-quality conditions is about 0.1 , its value for this reactor decreases from about 0.8 at $5 \mathrm{sccm}$ to 0.02 at $20 \mathrm{sccm}$. Further, $\mathrm{C}_{\mathrm{H}}\left(\mathrm{Si}-\mathrm{H}_{2}\right)$, closely related to efficiency deterioration due to light soaking, also decreases 1 at. $\%$ at $5 \mathrm{sccm}$ to 0.2 at. $\%$ at $20 \mathrm{sccm}$, keeping $\mathrm{C}_{\mathrm{H}}\left(\mathrm{Si}-\mathrm{H}_{2}+\mathrm{Si}-\mathrm{H}\right) \sim 6 \%$. The $\mathrm{C}_{\mathrm{H}}\left(\mathrm{Si}-\mathrm{H}_{2}\right) \sim 0.2 \%$ is significantly low compared to about $1 \%$ for the conventional device-quality films. Recently, we have introduced an equipment to make Schottky diode for evaluating the fill factor (FF) of a-Si:H films. The FF value after light soaking of $240 \mathrm{~mW} / \mathrm{cm}^{2}$ for $7.5 \mathrm{~h}$ was 0.53 . This value is much better than the best ones 0.47 obtained until now. It has been reported that FF and conversion efficiency of a-Si:H solar cell are estimated from the FF value of i-layer [9]. The value of $\mathrm{FF}=0.47$ above is estimated to correspond to the single junction pin solar cell of FF $\sim 0.64$ and stabilized conversion 
efficiency of about $9.4 \%$. The FF and conversion efficiency for the a-Si:H of FF $=0.53$ in our case are estimated to correspond to 0.78 and $12.3 \%$, respectively.

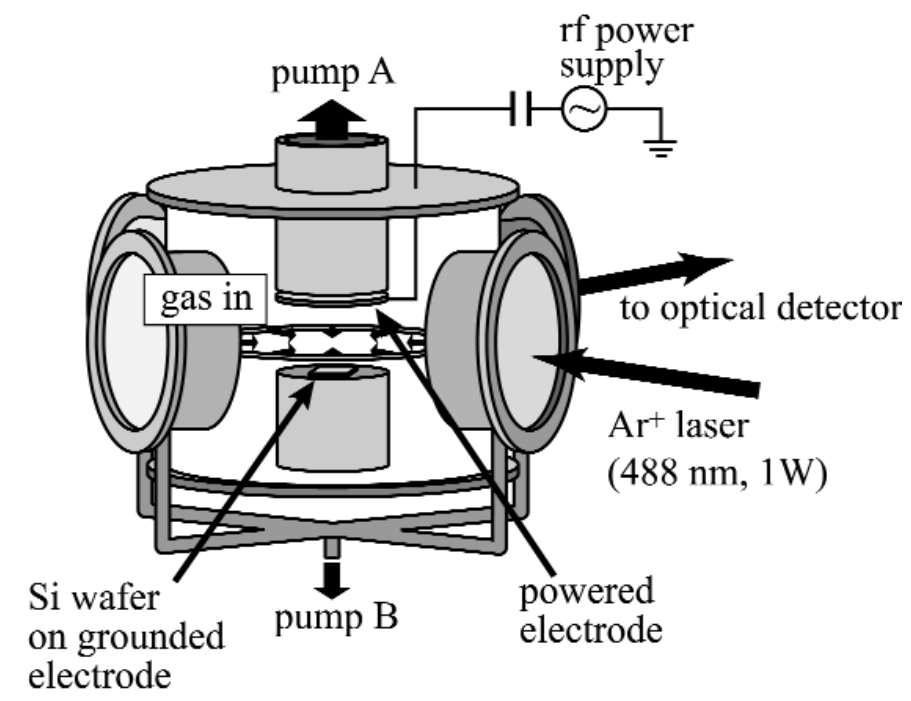

Fig. 3 Newly developed reactor which suppresses cluster growth both by thermophoretic force and by gas flow and evacuation without stagnation.

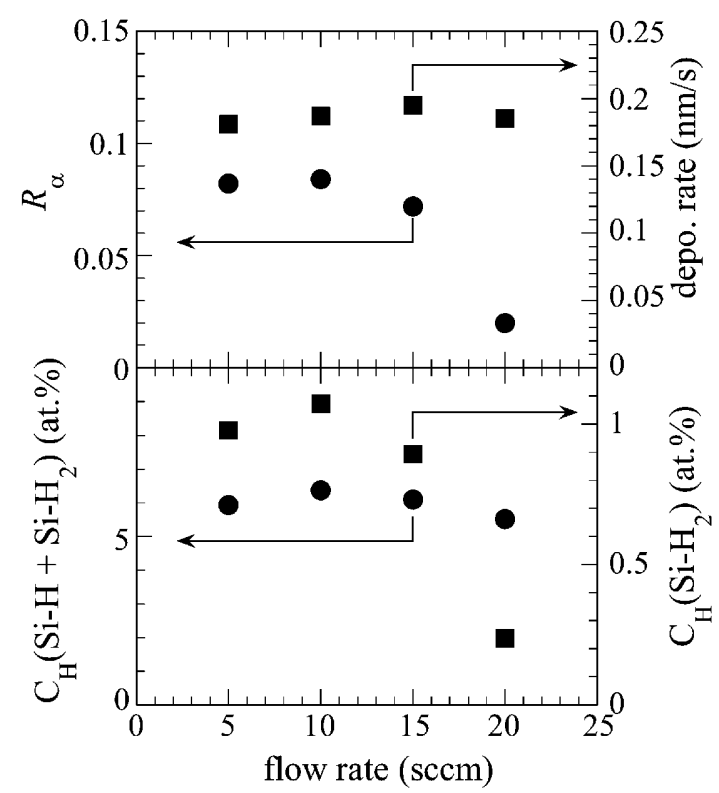

Fig. 4 Qualities of deposited a-Si:H films. Experimental conditions: $100 \% \mathrm{SiH}_{4}, 9.3 \mathrm{~Pa}, 28 \mathrm{MHz}, 10 \mathrm{~W}$, grounded electrode temperature $250{ }^{\circ} \mathrm{C}$. 


\section{CONCLUSIONS}

The clustering phenomena in $\mathrm{CCHF} \mathrm{SiH}_{4}$ discharges have been revealed fairly well using newly developed in situ observation methods of cluster growth. The a-Si:H films of quite high qualities compared to those prepared for the conventional device-quality conditions have been obtained by using the reactor in which the cluster growth is suppressed both by thermophoretic force and by gas flow and evacuation without stagnation. This result indicates that the qualities of a-Si:H films are much improved by suppressing the cluster growth even under high-speed-deposition conditions.

Recently, powder formation of various materials, such as $\mathrm{SiO}_{2}, \mathrm{SiN}$ and $\mathrm{CN}$, in gas phase have been tried, suggesting the study on clustering kinetics for mixed gases becomes important. While the clusters obtained in our experiments have been amorphous, those for $\mathrm{SiH}_{4}$ highly diluted by Ar have been $\mathrm{nm}$-size crystallized ones. Also, crystallized clusters have been obtained for $\mathrm{SiH}_{4}$ highly diluted by $\mathrm{H}_{2}$. It will be important to identify conditions for which clusters are crystallized, since crystallized clusters may improve film quality, while amorphous ones may degrade the quality.

\section{REFERENCES}

1. M. Shiratani, H. Kawasaki, T. Fukuzawa, T. Yoshioka, Y. Ueda, S. Singh, Y. Watanabe. J. Appl. Phys. 79, 104-109 (1996).

2. P. Roca i Cabarrocas. Proc. $2^{\text {nd }}$ Int. Conf. on Physics of Dusty Plasmas, Hakone, Japan, pp. 213-225 (1999).

3. M. Shiratani, S. Maeda, K. Koga, Y. Watanabe. Jpn. J. Appl. Phys. 39, 287-293 (2000).

4. K. Koga, Y. Matsuoka, K. Tanaka, M. Shiratani, Y. Watanabe. Appl. Phys. Lett. 77, 196-198 (2000).

5. J. Perrin and Ch. Hollenstein. In Dusty Plasmas, A. Bouchoule (Ed.), p. 77, Wiley, Chichester (1999).

6. M. Shiratani, S. Maeda, K. Koga, Y. Watanabe. Jpn. J. Appl. Phys. 39, 84-90 (2000).

7. Y. Matsuoka, M. Shiratani, T. Fukuzawa, Y. Watanabe, Kyo-Seon Kim. Jpn. J. Appl. Phys. 38, 4556-4560 (1999).

8. K. Koga, M. Kai, M. Shiratani, Y. Watanabe, N. Shikatami. Jpn. J. Appl. Phys. 41, L168-L190 (2002).

9. T. Nishimoto, M. Takai, M. Kondo, A. Matsuda. Proc. $28^{\text {th }}$ IEEE Photovoltaic Specialists Conf. In press. 